\title{
Hydrolysis of Eichhornia Crassipes to Glucose over Sulfonated Active Carbon Catalyst
}

\author{
Didi Dwi Anggoro*, Rispiandi and Purwanto \\ Chemical Engineering Department, Diponegoro University \\ Tembalang Campus, Semarang, Indonesia 50239 \\ *Corresponding: anggorophd@gmail.com
}

\section{Article history :}

Received 2 Oct 2014

Accepted 30 Apr 2015

\section{GRAPHICAL ABSTRACT}

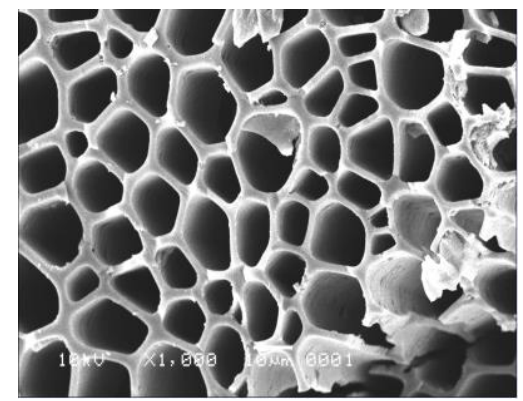

\begin{abstract}
Enzimatic process and acid hydrolysis process are common process for conversion of cellulose to glucose. Unfornately, the two processes are expensive process and korosif process. Hence, the new process, that use sulfonaned active carbon catalyst is important to developing. The sulfonated active carbon is made from carbonated coconut sheel under temperature at $350 \mathrm{oC}$. After carbonation, sulfonated active carbon soaked under sulphate acid $96 \%$ at $150 \mathrm{oC}$ until 15 hours. The result is then washed and dried, and tested catalyst characteristics in the form of $\mathrm{H}+$ capacity, pore size catalysts by used BET surface area, functional groups by used FTIR, and morphology catalyst structure by used SEM. Catalyst performance was tested in an autoclave reactor through a hydrothermal process with difference of the catalyst amount and temperature. The results showed that the test characteristics of $\mathrm{H}+$ capacity is $2.95 \mathrm{mmol} / \mathrm{g}$, the pore size is $29 \mathrm{~m} 2 / \mathrm{gr}$. FTIR analyze showed that the presence of sulfonate groups read at a wavelength of vibration $1750 \mathrm{~cm}-1$ and $1379 \mathrm{~cm}-1$. By SEM analyze showed that the morphological structure of sulfonated active carbon is more open than other catalyst. By testing catalyst, the highest conversion of glucose is $87.2 \%$.
\end{abstract}

Key words: Celluose, Glucose, eceng gondok, sulfonated active carbon

(C) 2015 Penerbit UTM Press. All rights reserved http://dx.doi.org/10.11113/mjfas.v11n2.368

\section{INTRODUCTION}

Biomass has the potential to be rich in lignocellulosic materials. Today in the developed countries started to do research and development there's even down to the level of production how to convert biomass materials into ethanol (Alico, et.al. 1982). Bioethanol is expected to gradually become an alternative fuel stations. As we know that gasoline is obtained from the refining of crude oil, while crude oil prices tend to fluctuate, while imports of crude oil and processed products to meet domestic demand also increased, it takes strategic measures to conserve conventional energy reserves, maintain availability of energy, and reduce foreign exchange expenditure of this sector (Kosaric, et.al., 1981).

Cellulose is made into a stage of cellulosic ethanol is converted into glucose, and glucose is converted to ethanol. The technology has been used for this is the process of enzymatic and acid hydrolysis. Both of these technologies are still having technical problems, ie for the price enzymatic enzymes are expensive and vulnerable to changes in operating conditions, while acid hydrolysis process is corrosive and cause waste, requiring the development of new technologies to improve the technical issues.

Acid hydrolysis proceeds in three steps. The reaction is initiated by a proton from the acid to interact quickly with glycosidic oxygen linking two sugar units, thus forming bonds conjugate acid. The split of the CO bond and the acid conjugated to cyclic carbonium ion then broke into sugar free and carbonyl groups are not stable. After the addition of water fast, carbonium intermidiet into sugar, as it re-released acid group $\mathrm{H}+$, and so on.

To solve the technical problems of the solid acid catalyst are made sulfonated activated carbon catalyst. This catalyst is made by reacting activated carbon with acid sulfuric acid. The group which containing sulfonate group $\mathrm{H}+$ could as acid site. The technology which used sulfonated activated carbon is a new new technology. This technology is being developed and studied in Japan and other countries. From several studies of this catalyst are conclude that this catalyst is capable to transforming cellulose into glucose. Onda, et al. (2008) studied the ability of some solid catalysts to convert the cellulose into glucose. The results showed sulfonated activated carbon has the best performance that the highest conversions are obtained. The sulfonated activated carbon catalyst used from sugar-based materials, which converted into carbon by pyrolysis process $(\mathrm{T}>300 \mathrm{oC})$. The sulfonization of carbon use sulfuric acid solution at a temperature of $150 \mathrm{oC}$ (Onda et al, 2008).

The carbon which used as catalyst support should be in the hydrocarbons polyaromatik structure form. In this structure, the catalyst will be allow for attached of 
sulfonate groups. Hence, the carbonization process carried at $400 \mathrm{oC}$ to form a structure poliaroamatik (Mochida et al, 2006). The advantages of activated carbon as catalyst support are acid and alkaline resistant, high temperature and high pressure resistant, inert, easy recycling (recovery), and has a large surface area (Mochida et al, 2006).

The process which use of sulfonated actived carbon catalysts has no corrosive process. The spent this catalyst are complete separation easily by filtration, and the separated this catalyst can be reactivated. So the product does not produce waste catalyst. The purpose of this research is to study the potential of Eichhornia Crassipes (Eceng Gondok) as cellulose source for produce glucose.

\section{METHODOLOGY}

The activated carbon was made from coconut shells, which was carbonized at temperature of $350 \mathrm{oC}$. The activated carbon was reduced in size to 60 mesh and was soaked in $96 \%$ sulfuric acid solution for 15 hours at a temperature of $150 \mathrm{oC}$. The catalyst was washed and dried. The characterization of catalyst was carried by $\mathrm{H}+$ capacity, BET, FTIR, and SEM.

The hydrolisis process was carried by autoclave. The dimension of autoclave equipment has volume of 250 $\mathrm{ml}$, height of $11 \mathrm{~cm}$, made of SS 304 (Figure 1). Before hydrolysis, the celluse material was heated at a temperature of $105 \mathrm{oC}$ and was reduced in size to 60 mesh.

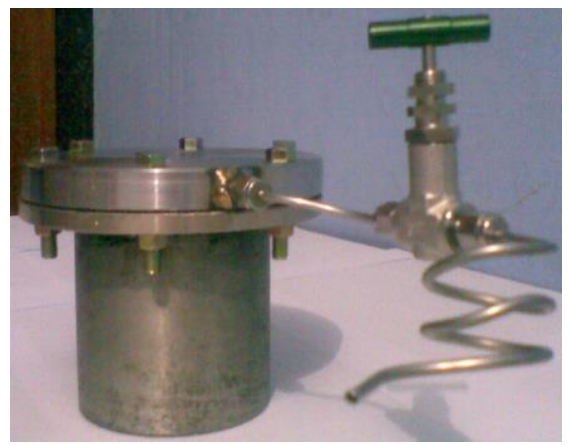

Figure .1 Autoclave equitment

Testing of catalyst was done with variable catalyst weight (i.e. 0-4 gram) and reaction temperature (i.e. 130$170 \mathrm{oC})$. The sample weight of 2 gram and aquadest volume of $200 \mathrm{~cm}$ every run of experiment. Analysis of glucose products use the method Antrone (9,10-Dihydro-9Oxsanthracene / C14H10O) $0.1 \%$ in sulfuric acid. Preparation of standard curve of total sugar made by dissolving $0.1 \mathrm{~g}$ of glucose in $100 \mathrm{~mL}$ of distilled water standards to obtain a concentration of $1000 \mathrm{ppm}$. The solution was then diluted with distilled water to obtain concentrations of 0 (control), 40, 80;120;160; 200 ppm. Each solution is then added to $5 \mathrm{~mL}$ of reagent Anthrone, then closed and mixed thoroughly. Once placed in a water bath at $100 \mathrm{oC}$ for 12 minutes, and cooled with water, and then carried out on the spectrometer readings absorbance maximum of $630 \mathrm{~nm}$ wavelength is the relationship between the absorbance to $\mathrm{mg}$ glucose. Determination of total sugar concentration contained in the sample was performed at $1 \mathrm{~mL}$ sample was diluted in a test tube in the same way as in the manufacture of a standard curve.

\section{RESULTS AND DISCUSSION}

The result of catalyst characterization indicated that the number of $\mathrm{H}+$ in the catalyst is $2.95 \mathrm{mmol} / \mathrm{g}$. This is mean that every $1 \mathrm{~g}$ of the catalyst contained $2.95 \mathrm{mmol}$ of $\mathrm{H}+$ ions. The $\mathrm{H}+$ ion is bounded to the sulfonate group which is expected to act as a catalyst in the process of hydrolysis to break down cellulose into glucose, as shown Figure 2 (Onda, at.al., 2008). From BET analyze, the surface area of the catalyst is $29 \mathrm{~m} 2 / \mathrm{g}$. The surface area of the catalyst is expected to play a role in the interaction of active centers on the catalyst surface with cellulose (Mochida et al 2006).

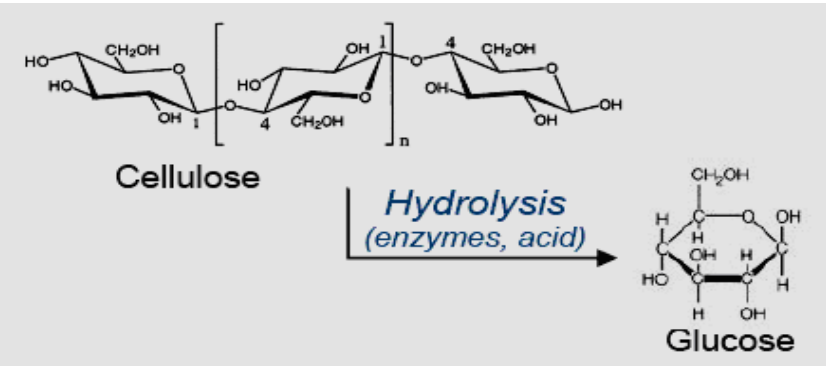

Figure 2. Reaction of break down cellulose into glucose (Onda, at.al., 2008)

The FTIR analyzed results was showed on Figure 3. The bands peak at a wavelength of $\lambda=1750 \mathrm{~cm}-1$ and $\lambda=1379 \mathrm{~cm}-1$ of sulfonated activated carbon is difference with activated catalyst. At those wavelengths detected the presence of sulfonate groups $\mathrm{SO} 3 \mathrm{H}$. This result indicated that activated carbon after sulfonation containing sulfonate groups as part of an active site of the activated carbon catalyst.

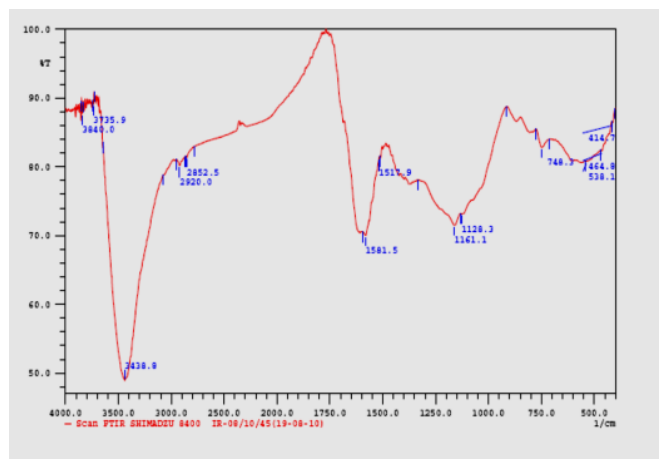

(a) 


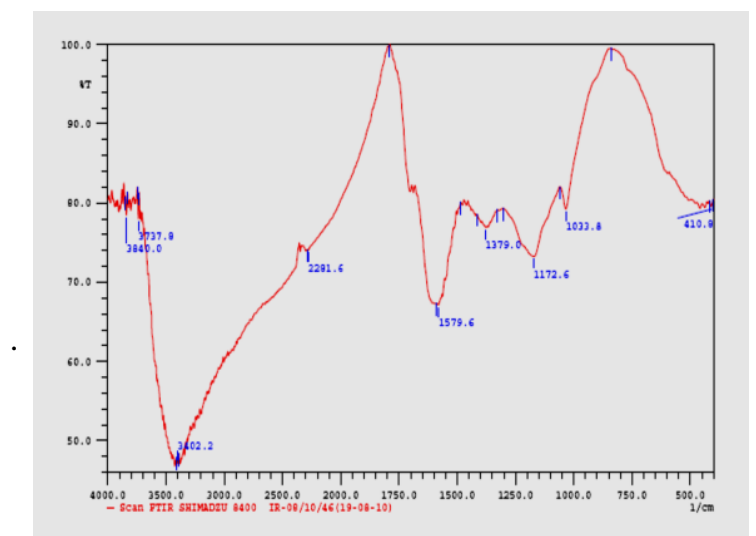

(b)

\section{CONCLUSION}

Silicon Nitride thin films were deposited using a commercial RF magnetron sputtering system following the non reactive sputtering routine. The influence of sputtering pressure was investigated on films` properties like growth rate, refractive index, surface roughness, surface morphology, chemical bonding and microstructure.

\section{REFERENCES}

[1] Mousinho, A. P.; Mansano, R. D.; Zambom L. S.; Passaro A. J. Phys. Conf. Ser. 370 (2012) 012015

[2] Liu, Y.; Lin, I.; Zhang, X. Mater. Sci. Eng. A. 489 (2008) 294.

[3] Tiwari, R.; Chandra, S.; Adv. Mater. Res. 254 (2011). 187.

[4] Sandland, J.G. PhD. Thesis M.I.T. 2004.

[5] Smietana, M.; Brabant, D.; Bock,W. J.; Mikulic, P.; Eftimov, T. J. Lightwave Technol. 30 (2012) 1185.

[6] Chapman, B.; Glow Discharge Processes: Sputtering and Plasma Etching. John Wiley \& Sons, Inc. (1980).

[7] Hirohata, Y.; Shimamoto, N.; Hino, T.; Yamashima, T.; Yabe, K.. Thin Solid Films 253 (1994) 425.

[8] Signore, M. A.; Sytchkova, A.; Dimaio, D.; Cappello, A.; Rizzo, A. Opt. Mater. 234 (2012) 632..

[9] Rouchon, D.; Rochat, N.; Gustavo, F.; Chabli, A.; Renault, O.; Besson, P. Surf. Interface Anal. 34 (2002) 445.

[10] Artieda, A.; Barbieri, M.; Sandu, C. S.; Muralt, P. J. Appl. Phys. 105 (2009) 024504.

[11] Lee, H. C.; Kim, G. H.; Hong, S. K.; Lee, K. Y.; Yong, Y. J.; Chun, C. H.; Lee, J. Y. (1995). Thin solid films 261 (1995) 148.

[12] Xu, G.; Jin, P.; Tazawa, M.; Yoshimura, K. Thin Solid Films. 425 (2003) 196.

[13] Ma, T.P. IEEE Trans. Electron Dev. 45 (1998) 680.

[14] Seiffe, J.; Gautero, L.; Hofmann, M.; Rentsch, J.; Preu, R.; Weber, S.; Eichel, R. A. J. Appl. Phys. 109 (2011) 034105.

[15] Spinelli, P.; Hebbink, M.; van Lare C.; Verschuuren, M.; de Waele, R.; Polman,A. Optical Society of America (2010).

[16] Lin, P. T.; Singh, V.; Kimerling, L.; Agarwal, A. M. Appl. Phys. Lett. 102 (2013) 251121.

[17] Shi S.; Wang X.; Xu C.; Yuan J.; Fang J.; Jiang S.; Liu S. (ICEPT 2013) IEEE.

[18] Wu, P. H.; Lin, I. K.; Yan, H. Y.; Ou, K. S.; Chen, K. S.; Zhang, X. Sens. Actuator B-Phys. 168 (2011) 117

[19] Sousa, R.; Ribeiro, J. F.; Sousa, J. A.; Montenegro, R. T.; Goncalves, L. M.; Correia, J. H. (2013)
The result showed that the sputtering pressure has an imperative effect on the properties of magnetron sputtered thin films. Good quality and near stochiometric silicon nitride thin films with minimum surface value of 1.2 $\mathrm{nm}$, at growth rate $7.03 \mathrm{~nm} / \mathrm{min}$ were obtained under 3 mTorr sputtering pressure.

The refractive index, surface roughness, excess silicon content and stress of deposited thin films increased linearly with the sputtering pressure. However, an optimum sputtering pressure value was observed during the characterization for growth rate. The growth rate was increased until that optimum value and then started decreasing due to back diffusion and scattering effect.

As a future work, the stoichiometry of silicon nitride thin films produced by RF magnetron sputtering can be adjusted by bleeding nitrogen gas during the deposition but this could affect the growth rate of thin films.

\section{ACKNOWLEDGEMENTS}

The authors wish to thank the center for graduate studies, Universiti Tun Hussein Onn Malaysia (UTHM) and Ministry of Education, Malaysia for supporting of this work through FRGS vot 1048. 